\title{
0 pragmatismo das fontes profissionais de informação: perspectiva teórica não-conspirativa da relação entre assessores de imprensa e jornalistas
}

The pragmatism of the professional sources of information: a non-conspiring theoretical perspective of the relationship between press aides and journalists

El pragmatismo de las fuentes profesionales de información: perspectiva teórica no conspirativa sobre la relación entre los asesores de prensa y periodistas

\section{Vasco Ribeiro}

- Doutor em Ciências da Comunicação pela Universidade do Minho, Portugal

- Mestre em Comunicação Política pela Faculdade de Letras da Universidade do Porto (Flup)

- Licenciado em Comunicação Social pela Escola Superior de Jornalismo (ESP), de Porto, Portugal

- Leciona Assessoria de imprensa, Relações públicas, Comunicação empresarial e Comunicação política em quatro cursos da Flup e é professor convidado da Porto Business School

- Profissionalmente foi assessor de imprensa e diretor de comunicação na Assembleia da República, no Parlamento Europeu, na Reitoria da Universidade do Porto, na Câmara Municipal do Porto

- Autor do livro Fontes sofisticadas de informação

- E-mail:vribeiro@letras.up.pt 


\section{Resumo}

Tendo como base a literatura existente na sociologia do jornalismo, procura-se com este artigo compreender o papel dos assessores de imprensa enquanto peças basilares no processo noticioso e, em particular, tentar perceber até que ponto eles podem guiar e condicionar o trabalho jornalístico. Evitando posições conspirativas e maniqueístas, demonstra-se no texto uma tendência pragmática de indução noticiosa praticado por assessores de imprensa, relações-públicas, consultores de comunicação, porta-vozes e outras fontes que trabalham profissionalmente a informação.

\section{PALAVRAS-CHAVE: ASSESSORIA DE IMPRENSA・RELAÇÕES PÚBLICAS・JORNALISMO • FONTES DE INFORMAÇÃO.}

\section{Abstract}

Based on the existing literature in journalism sociology, this article seeks to understand the role of press aides as basic pieces in news making and to particularly try to understand to what extent they can guide the journalistic work. Avoiding conspiring and Manichean positions, it is shown in the text that there is a pragmatic trend of news induction practiced by press aides, public relations, representatives, communication advisors, spokespersons and other sources that work with information professionally.

\section{KEYWORDS: MEDIA RELATION•PUBLIC RELATIONS • JOURNALISM・SOURCES OF INFORMATION}

\section{Resumen}

Sobre la base de la literatura existente en la sociología del periodismo, se procura con este artículo comprender el papel de los asesores de prensa como piezas basilares en el proceso de noticias y, en particular, tratar de entender hasta qué punto ellos pueden orientar y condicionar el trabajo periodístico. Evitando posiciones conspirativas y posiciones maniqueas, se demuestra en el artículo una tendencia pragmática de inducción noticiosa de practicada por asesores ee prensa, relaciones públicas, consultores de comunicación, portavoces y otras fuentes que trabajan profesionalmente a la información. 


\section{ANO 12 • NÚMERO $22 \cdot 1^{0}$ sem. 2015 • ORGANICOM O PRAGMATISMO DAS FONTES PROFISSIONAIS DE INFORMAÇÃO: PERSPECTIVA TEÓRICA NÃO-CONSPIRATIVA DA RELAÇÃO ENTRE ASSESSORES DE IMPRENSA E JORNALISTAS}

"Antes de ler o seu próximo jornal, assistir ao próximo noticiário televisivo ou desfolhar a próxima revista, pergunte a si mesmo: Sei realmente donde veio a informação que vou digerir? Quem é que quer que eu leia isto?"

C

om este primeiro parágrafo da obra The invisible persuaders David Michie (1998), jornalista britânico, questiona, perentoriamente, uma das atividades que mais parecem contribuir para a indução noticiosa: a assessoria de imprensa.

De fato, o excerto aqui publicado é particularmente eloquente na forma como traduz as dúvidas, suspeitas, incertezas sobre a origem - e, consequentemente, sobre a veracidade - da informação que consumimos diariamente.

Vários estudos comprovam a influência da assessoria de imprensa na produção noticiosa (Franklin, Lewis e Williams, 2010; Ribeiro, 2010), enquanto técnica para parasitar a credibilidade do jornalismo com o intuito de transmitir informações buriladas para um determinado fim. Importa ressalvar, contudo, que essa influência não só é perfeitamente legítima faz parte das regras do jogo mediático, digamos - como tem diferentes cambiantes, em função do comportamento do jornalista e das dinâmicas próprias da redação onde este realiza a sua atividade. E não uma obsessiva visão conspirativa do sistema capitalista e dos agentes políticos, bem patentes nas históricas obras de Vance Packard (1957), Daniel Boorstin (1961), Edward Herman e Noam Chomsky (1988) ou ainda Ignacio Ramonet (2000). É um objetivo que tentaremos seguir no presente artigo, que reúne um conjunto de citações que foram traduzidas por nós.

\section{INTERAÇÃO ENTRE JORNALISTAS E FONTES DE INFORMAÇÃO}

Num inquérito que o britânico Jeremy Tunstall (1974: p. 168) realizou junto a 208 jornalistas de Londres, ele verificou que dois terços consideravam as fontes "úteis" e "cordiais", enquanto mais de 50\% admitiam contatar a assessoria de imprensa para desenvolver um trabalho jornalístico. Mas o mais surpreendente, e até mesmo paradoxal, é que $46 \%$ consideravam que as fontes "ajudam mais os jornalistas"; $51 \%$, que se ajudam de forma "igual"; e 3\%, que "os jornalistas ajudam mais a fonte" (Tunstall, 1974, p. 185). São dados obtidos por resposta a um inquérito e que demonstram não uma alienação dos jornalistas, mas uma necessidade de reafirmar valores de isenção e objetividade, assim como uma tentativa de "manterem em segredo" (Tunstall, 1974, p. 87) as fragilidades da sua atividade.

Ainda numa perspectiva mais focada na interação, o norte-americano Herbert Gans (1979) desenvolveu um estudo sobre 0 comportamento dos jornalistas nas redações das cadeias de televisão norte-americanas CBS e NBC e das revistas Time e Newsweek, entre 1967 e 1975, e demonstrou que a fonte, mesmo sendo um fator crucial, só tem capacidade de influência na qualidade da informação produzida pelos media. Gans (1979, p. 80, 81) constatou que as fontes conhecidas, como os membros ou representantes de grupos de interesse organizados da sociedade (que não apresentam as mesmas características ou igual relevância), têm a sua ação limitada porque não podem "fornecer informações até serem contatadas por um elemento de uma organização noticiosa" e que, mais grave ainda, só são escolhidas se forem "consideradas apropriadas para a audiência". Aliás, a famosa analogia que compara a relação entre jornalistas e fontes de informação a uma dança nasce com essa obra de Gans, Deciding what's news, é a melhor forma de perceber como o autor interpretava essa interação.

0 mesmo autor demonstrou também que há fatores que definem a escolha de determinadas fontes, levando os jornalistas a preferirem aquelas que garantam: 1) incentivos; 2) poder; 3) capacidade de fornecer informações credíveis à publicação; e 4) proximidade geográfica e social (Gans, 1979, p. 117). No fundo se trata de identificar as fontes de informação em função dos seus atributos de fidelidade (BERLO, 2003) e do seu estatuto de poder (Molotch; Lester, 1993). 0 autor percebeu que os jornalistas preferem fontes ativas, "ansiosas, agradáveis e recalcitrantes" (Gans, 1979, p. 117), pois constituem um fator de incentivo à sua 


\section{ANO 12 • NÚMERO $22 \cdot 1^{0}$ sem. 2015 - ORGANICOM O PRAGMATISMO DAS FONTES PROFISSIONAIS DE INFORMAÇÃO: PERSPECTIVA TEÓRICA NÃO-CONSPIRATIVA DA RELAÇÃO ENTRE ASSESSORES DE IMPRENSA E JORNALISTAS}

utilização. Trata-se aqui de uma referência direta às fontes profissionais de informação, que ele classificou de "distribuidores de poder" (power distributors). Disse ainda, a propósito, que "já não se pode viver sem assessoria de imprensa" (Gans, 1979, p. 118).

No entanto, o poder da fonte advém em boa medida da hierarquia da credibilidade, da capacidade de fornecer informações pertinentes e de criar eventos noticiáveis, por contraponto àquelas fontes que não sabem o que é uma notícia ou que são responsáveis por "muitos releases (...) que acabam no balde do lixo sem serem lidos" (Gans, 1979, p. 122). Da mesma forma que as fontes mais próximas potenciam a sua aceitação dentro de toda esta estrutura informativa, que é espelho da sociedade.

Timothy E. Cook (1989: p. 30) corrobora essa ideia, mas ressalva que os dois intervenientes "dormem juntos" (Cook, 1989, p. 102), numa relação de equilíbrio de poder onde nenhuma parte pode perceber que é conscientemente dominada. 0 mesmo autor, que estuda em particular as fontes profissionais norte-americanas, considera ainda que o newsmaking não é um processo linear e unidirecional, mas sim interativo e interdependente entre fontes e jornalistas. As fontes oficiais e os jornalistas "controlam recursos importantes e interessantes" (Cook, 1998, p. 12) da produção noticiosa, ou seja, as fontes ditam as regras sobre os aspetos importantes da dinâmica informativa e "os jornalistas decidem o que é interessante noticiar" (Cook, 1998, p. 13).

\section{O PRAGMATISMO DAS FONTES DE INFORMAÇÃO}

Há um conjunto de autores que não têm uma visão conspirativa ou maniqueísta das fontes, enquanto fator central na produção noticiosa. Veem a circulação da informação como um processo de troca e negociação inerente à legítima defesa dos interesses específicos de cada um dos intervenientes. David Altheide (1976), por exemplo, começou por dividir o processo noticioso entre newsworkers e newsmakers, em um estudo que analisa as cadeias de televisão nos Estados Unidos. Os primeiros (jornalistas) são responsáveis por identificar as oportunidades de notícia, selecionar as que interessam, realizar a cobertura noticiosa e apresentar a estória. Os segundos (assessores de imprensa, sobretudo) "desenvolvem estratégias de promoção para procurar ter acesso à cobertura noticiosa" (Altheide, 1976, p. 113-114).

Na problemática definição do que é notícia, as fontes têm duas opções: ou "são passivas e ficam à espera que, um dia, as câmaras iluminem as suas ações/problemas"; ou são ativas e "desenvolvem estratégias para terem cobertura noticiosa" (Altheide, 1976, p. 115). Mas, para além de ativas e não-altruístas, as fontes profissionais de informação devem apresentar material noticiável e confiável. Os assessores de imprensa "embrulham" as suas estórias com uma "formatada linguagem jornalística" e uma aguda noção de oportunidade noticiosa, que os leva a simular 'cachas' onde só os jornalistas mais atentos percebem que "eles só pretendem promoção" (Altheide, 1976, p. 119).

Tradicionalmente, os jornalistas desenvolvem as suas potenciais notícias perguntando quem, o quê, onde, quando e por quê" (Altheide, 1976, p. 179). Por isso, o autor defende que essas questões pesam no processo de produção de notícias. Por quê passa por uma intenção de mostrar como as notícias descontextualizam e recontextualizam os acontecimentos noticiados. Quem foca-se, logicamente, em quem dá a notícia e aqui ganham as fontes oficiais por serem reconhecidas na redação e, consequentemente, pelas audiências. O quêreporta novamente a quem promove o acontecimento e baseia-se nos "fatos" e na "verdade" dos mesmos. Onde e quando têm por base a proximidade espacial' e temporal dos fatos (Altheide, 1976, p. 180-195). 


\section{ANO 12 • NÚMERO $22 \cdot 1^{0}$ sem. 2015 • ORGANICOM O PRAGMATISMO DAS FONTES PROFISSIONAIS DE INFORMAÇÃO: PERSPECTIVA TEÓRICA NÃO-CONSPIRATIVA DA RELAÇÃO ENTRE ASSESSORES DE IMPRENSA E JORNALISTAS}

Foi, de resto, com o objetivo de tentar perceber como agiam as fontes profissionais de informação, assim como os seus meios operacionais, recursos, níveis organizativos, atividades e estratégias, que Stephen Hess (1984), em The government/ press connection: press officers and their offices, descreveu o modus operandi dos gabinetes de comunicação de cinco agências federais norte-americanas. Tal como os anteriores investigadores, apesar de numa perspectiva diferente, esse autor identifica a rotina como principal motor de produção de notícias.

Hess (1984, p. 108) elogia ainda o profissionalismo e o rigor dos assessores de imprensa que "trabalhavam afincadamente e apresentavam um produto útil (...). Por vezes, as declarações à imprensa eram mais precisas do que os relatos apressados escritos por repórteres generalistas". Destaca também o trabalho sistemático, ordenado e de alto interesse público desses gabinetes. Mas adverte que "ordenado pode, em alguns casos, ser um eufemismo para controlado" (Hess, 1984, 115 - grifo nosso). Tal como Gans (1978), Hess (1984) defende que na relação jornalistas-fontes há uma reação recíproca, mais do que uma ação voluntarista de uma das partes. Ou seja, quem despoleta e gere as notícias diverge de caso para caso. Os assessores de imprensa mais competentes conseguem prolongar os efeitos mediáticos de uma notícia positiva, ao mesmo tempo que se revelam capazes de atenuar os fatos negativos. Conhecem muito bem as estruturas organizativas dos media, assim como os seus agentes, as suas preferências e o timing certo para realizar os acontecimentos. Aliás, trata-se de uma posição igualmente partilhada pelo professor brasileiro Manuel Carlos Chaparro (2001, p. 43).

Na hora de escrever, na rotina da produção e dos procedimentos profissionais (os conscientes e os inconscientes), a perspectiva das fontes influencia, inevitavelmente, a decisão jornalística - e quanto mais competentes elas se tornam, mais capazes são de determinar enfoques, relevâncias e até títulos, na narração jornalística.

0 professor e investigador inglês Jerry Palmer (2000), realizou um aprofundado estudo para perceber as razões pelas quais as fontes oficiais se aproximam dos jornalistas ou permitem (ou não permitem) ser abordados. Com esses propósitos, 0 autor analisou um escândalo sexual e uma ação da Greenpeace contra a petrolífera British Petroleum (BP). Percebeu, então, que as fontes usam vários motivos e várias técnicas para integrar o espaço mediático de forma positiva. Como "motivos", as fontes políticas exibem o direito democrático ao conhecimento público das políticas, a alteração do perfil da organização, as tentativas para criar uma imagem pública com notoriedade, a entrada nos assuntos que dominam a ordem do dia e a tentativa de limitar um eventual dano ou incidente (Palmer, 2000, p. 47-52). Como "técnicas", o autor destaca a criação de uma relação credível e confiável com os jornalistas; a necessidade de validação da informação pelo jornalista para passar a mensagem; o apelo à sua consciência jornalística; a definição do timing para libertar a informação e do local onde esta se liberta de forma a servir os interesses jornalísticos; e a adaptação das informações aos valores-notícia.

\section{A CRESCENTE DEPENDÊNCIA DO JORNALISMO FACE ÀS FONTES DE INFORMAÇÃO}

Aos conteúdos fornecidos pelas fontes às organizações noticiosas Oscar Gandy (1982), sociólogo e professor de comunicação na Universidade de Pensilvânia, deu o nome de informação subsidiada (information subsidies). A informação subsidiada é, para ele, um texto que chega a uma redação já formatado em estilo jornalístico e que, por isso mesmo, é automaticamente aproveitado para publicação. Surge, dessa forma, esse conceito muito colado ao 'patrocínio financeiro' ou 'subsídio', pois esses mesmos textos representam ausência de trabalho e investimento por parte das organizações noticiosas. Falamos dos press releases, dos comunicados e das pautas. 


\section{ANO 12 • NÚMERO $22 \cdot 1^{0}$ sem. 2015 - ORGANICOM O PRAGMATISMO DAS FONTES PROFISSIONAIS DE INFORMAÇÃO: PERSPECTIVA TEÓRICA NÃO-CONSPIRATIVA DA RELAÇÃO ENTRE ASSESSORES DE IMPRENSA E JORNALISTAS}

Esse investigador demonstrou, na obra Beyond agenda setting: information subsidies and public policy (1982), que as fontes de informação estão interessadas em fornecer dados que reduzam o trabalho dos jornalistas. Dessa forma, aumentam 0 controle sobre as notícias, diminuem as reportagens de investigação e controlam os temas abordados na opinião pública (Gandy, 1982, p. 15). No fundo, são "tentativas de exercer influência sobre as ações dos outros através do controle do conteúdo e do acesso à informação" (Gandy, 1982, p. 61). Neste âmbito, o autor identifica a publicidade, as relações públicas, a consultoria de comunicação e a informação governamental, parlamentar ou política em geral como as principais formas de produção de informação subsidiada.

Ao analisar o comportamento dos jornalistas na ronda diária exigida pela cobertura das forças de segurança, tribunais e governos locais norte-americanos, Mark Fishman (1980) já antes constatara a disponibilidade natural das "fontes promotoras" para fornecerem informações aos media. Este processo, que o autor apelida de "subsídio invisível de notícias" (invisible bureacratic subsidy of news) (Fishman, 1980, p. 150), permite aos jornalistas produzirem peças em pouco tempo e com pouco trabalho. E procuram sempre obter "promoção e legitimação" (Fishman, 1980, p. 152).

E são essas mesmas fontes que, na opinião do jornalista norte-americano Bernard Roshco (1984), constituem a principal causa do enviesamento da pretensa objetividade jornalística. Isso acontece porque as fontes profissionais apenas fornecem "as perspectivas que desejam promover" (Roshco, 1984, p. 19) ou, como Fishman (1980, p. 152) já havia alertado, "os assessores de imprensa escrevem press releases com estórias já formatadas".

Ao produto jornalístico resultante exclusivamente das informações difundidas pelas relações públicas, Nick Davies (2008, p. 59), investigador e jornalista do britânico Guardian, chamou de 'churnalism':

0 'churnalism' acontece quando os jornalistas deixam de executar as funções mais básicas da profissão. Quando são incapazes de dizer aos seus leitores a verdade do que está a acontecer; quando não saem à rua para encontrar estórias, mas, pelo contrário, tornam-se processadores passivos de material informativo que vem produzido à medida pelas relações públicas, seja real ou artificial, importante ou trivial, verdadeiro ou falso.

\section{NEGOCIAÇÃO PERMANENTE}

Sabendo que os jornalistas preferem fontes conhecidas, regulares e autorizadas, um grupo de investigadores canadenses liderado por Richard Ericson (1989) realizou um importante estudo, Negotiating control, com o objetivo de perceber como as fontes trabalham para "proteger a sua organização da intrusão de jornalistas, enquanto ao mesmo tempo conseguem publicidade favorável, que é vista como um importante modo de manter o controle sobre o ambiente organizacional" (Ericson; Baranek; Chan,1989, p. 8). A partir dessas premissas, os autores construíram uma grelha de análise composta por uma zona de vanguarda (front regions) e uma outra de retaguarda (back regions), com diferentes graus de reserva (enclosures) e de abertura (disclosures) na gestão da informação para os media(Ericson; Baranek; Chan,1989, 287-302). Com essa metodologia, os investigadores procederam igualmente à tipificação das fontes de acordo com a forma como lidam com os jornalistas ao serviço das suas organizações: secreta (secrety), confidencial (confidence), censura (censorship) e publicitária (publicity) (Ericson; Baranek; Chan,1989, p. 9). Interessa referir que, para os autores, as zonas de retaguarda representam os espaços onde o trabalho organizacional transpira e onde as decisões são tomadas, pelo que são áreas restritas e só frequentadas por agentes ao serviço da organização (Ericson; Baranek; Chan,989, p. 10). Há também entidades, maioritariamente empresas, centros de investigação e exército, que se tornam secretas por ser esta a única forma de protegerem a produção dos seus 


\section{ANO 12 • NÚMERO $22 \cdot 1^{0}$ sem. 2015 - ORGANICOM O PRAGMATISMO DAS FONTES PROFISSIONAIS DE INFORMAÇÃO: PERSPECTIVA TEÓRICA NÃO-CONSPIRATIVA DA RELAÇÃO ENTRE ASSESSORES DE IMPRENSA E JORNALISTAS}

bens e serviços. Nestes casos, as fontes de informação definem estratégias defensivas e reativas capazes de prevenir falhas ou minimizar danos quando acontece uma crise, sempre numa constante dialética entre o que pode ser revelado e o que deve manter-se sob reserva. Em contraponto, a fonte confidencial caracteriza-se pela abertura da zona de retaguarda, que ocorre quando há vantagens em manter uma determinada audiência controladamente informada. No estabelecimento da confidencialidade, desenvolvem-se entre fontes e jornalistas dispositivos interpessoais complexos e legais, de forma a manter, de fato, o sigilo. A fonte censora gere o acesso à zona de vanguarda de acordo com os seus interesses organizativos. Por isso simula abertura e disponibilidade para informar, por exemplo através de um porta-voz, de modo a criar na opinião pública uma ideia de transparência. Esse trabalho de censura é maioritariamente desenvolvido por relações públicas, assessores de imprensa, porta-vozes e outros consultores de comunicação.

A sua ação passa pela edição. Logo, a censura de material provém da sua própria organização e os jornalistas, por sua vez, fazem a edição e a censura do material das fontes conforme lhes pareça adequado. 0 próprio ato da publicidade é simultaneamente um ato de censura (Ericson; Baranek; Chan, 1989, p. 291).

Por último, a fonte publicitária inclui as organizações que possuem equipas de relações públicas e que desenvolvem uma atividade proativa na divulgação dos serviços e produtos de uma empresa.

Ericson, Baranek e Chan, (1989, p. 377-378)) defendem ainda a importância da negociação entre fontes e jornalistas durante o processo de produção noticiosa. Para os autores, "as notícias são um processo de transação entre os jornalistas e as suas fontes". Eles não concordam com aqueles que dizem que os órgãos de comunicação social dependem em excesso das fontes de informação, transformando os jornalistas em meros "canos condutores" e "segundos definidores". Nesse sentido, advogam que, "do ponto de vista das fontes, os meios de comunicação social são extremamente poderosos, possuindo elementos-chave que muitas vezes lhes dão vantagem". Ressalvam, no entanto, que há fontes mais poderosas do que outras na criação de rotinas informativas e na definição dos contornos do debate público. 0 controle do processo noticioso varia de caso para caso, dependendo do contexto, do tipo de fontes envolvidas, do tipo de órgão de comunicação social implicado e do assunto em causa, levando em consideração que o jornalista tem sempre a última palavra.

Os autores descreveram também o comportamento das fontes em cenários de crise e compreenderam que estas são mais "cooperantes com os media porque procuram ganhar a confiança dos jornalistas" (Ericson; Baranek; Chan,1989, p. 381), o que implica a articulação com certos interesses e valores. Por sua vez, a fonte sente que pode confiar no jornalista ou no meio de comunicação quando tem a certeza de que os fatos que revelar serão, qualquer que seja a natureza dos mesmos, tratados com razoabilidade nas notícias e até abordados segundo uma perspectiva favorável aos valores e interesses da organização (Ericson; Baranek; Chan,1989, p. 382).

Por outro lado, quando há uma intenção censória, são identificadas várias técnicas que as fontes profissionais usam para promover uma mensagem, como "fornecer informações parciais pelo uso de citações citáveis (Ericson; Baranek; Chan, 1989, p. 383); utilizar a redundância para limitar a discussão pública sobre um determinado assunto; editar press releases com os fatos principais e citações apresentadas como factuais; ou produzir vídeos para jornalistas de televisão e gravações para os de rádio. Essas premissas já foram, de resto, referenciadas no anterior trabalho desses autores (Ericson; Baranek; Chan, 1987).

As fontes atuam, assim, com base numa estratégia dual: ora investem nas relações informais baseadas na confiança, ora nas relações formais assentes na censura. Donde o grande objetivo das relações públicas é dar a ideia de que se esforça 


\section{ANO 12 • NÚMERO $22 \cdot 1^{0}$ sem. 2015 - ORGANICOM O PRAGMATISMO DAS FONTES PROFISSIONAIS DE INFORMAÇÃO: PERSPECTIVA TEÓRICA NÃO-CONSPIRATIVA DA RELAÇÃO ENTRE ASSESSORES DE IMPRENSA E JORNALISTAS}

por colocar a descoberto fatos, quando realmente está, ao publicitá-los, a encobrir informação. Ou seja, quanto mais transparente é uma organização, maior é o controle que exerce sobre a sua própria informação (Ericson; Baranek; Chan, 1989, p. 383/384). Refira-se ainda que a falta de conhecimentos especializados sobre as matérias de cobertura (Gans, 1979), a falta de tempo e os condicionamentos organizacionais e culturais dos próprios media potenciam o recurso pelos jornalistas à ajuda dos colegas de profissão para construírem as notícias (Ericson; Baranek; Chan, 1989, p. 393).

Já as fontes são mais pragmáticas na sua abordagem às organizações noticiosas. Conhecendo a rotina que caracteriza o trabalho jornalístico, preocupam-se mais se as notícias têm poder de influência e utilidade do que se revelam isenção, pertinência e equilíbrio. Aliás, as fontes chegam mesmo a condicionar os jornalistas que não se mostrem "simpáticos" e "colaboracionistas" (Ericson; Baranek; Chan, 1989, p. 393).

\section{MODOS DE SABER USAR A FONTE}

O professor de jornalismo Philip Schlesinger (1990), para além de considerar os estudos anteriormente referidos demasiado mediacentrics, discorda da ideia dos "definidores primários" (Hall, 1993). 0 autor parte da premissa de que na esfera pública as fontes não representam um bloco único, mas antes um conjunto de interesses diferentes, concorrentes e antagónicos.

$O$ autor escocês critica, assim, autores como Stuart Hall (1993) e James Curran (1996) pela 'visão marxista da fonte'2, porque: 1) definem "definidores primários" como se se tratasse de um "todo unificado"; 2) acusam as fontes de usar o off-the-record para construir a história como se essa prerrogativa não pertencesse (e fosse dada) ao jornalista; 3 ) assumem que as fontes têm interesses e "vozes" comuns e consensuais; e 4) o "acesso estruturado" deve ser visto como uma ocorrência temporal.

Diante disso, o jornalista deve ter como "bitola ideal de análise das fontes" (Schlesinger, 1990, p. 79) pelo menos as seguintes condições: 1) verificar se a mensagem está "bem definida e num enquadramento otimizado em termos de valores-notícia", bem como se apresenta "boa localização e uma distribuição (...) bem direcionada às audiências"; 2) cultivar, se possível, "boas pré-condições comunicativas de sucesso, como, por exemplo, ter um relacionamento simpático"; 3), "em oposição, deve prever, neutralizar, antecipar ou desacreditar" tentativas de manipulação da fonte. Essas premissas têm, de alguma forma, por base a "fidelidade da comunicação" (Berlo, 1960), os "valores-notícia" (Galtung, Ruge, 1965) e "pertinência na utilização das fontes" (Gans, 1979).

Para Schlesinger (1990), a função estratégica das fontes comporta os seguintes aspectos: a institucionalização, porque servem os interesses do estado, de grupos de pressão e de outros atores sociais; o financiamento, porque fornecem informação útil e "subsidiada" às organizações noticiosas, tal como Gandy (1982) refere; e, por último, o capital social que legitima todo o sistema mediático, assumindo-se como "sangue do jornalismo" (Mencher, 1991).

A abordagem da sociologia do jornalismo pela perspectiva da fonte desenvolvida neste trabalho, mesmo não se tratando de uma ruptura, deu origem a novos estudos (Gumg, 1993; 1995; Manning, 1998), os quais vieram a revelar-se mais acutilantes e críticos para as fontes profissionais do que as teorias de Schlesinger.

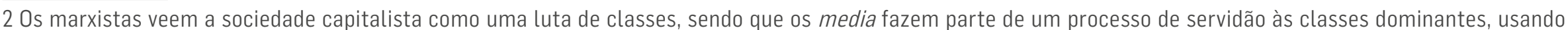

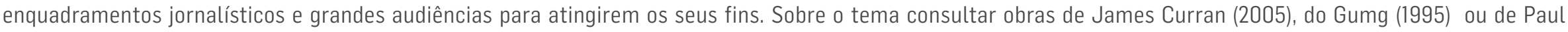
Manning (2001). 


\section{ANO 12 • NÚMERO $22 \cdot 1^{0}$ sem. 2015 - ORGANICOM O PRAGMATISMO DAS FONTES PROFISSIONAIS DE INFORMAÇÃO: PERSPECTIVA TEÓRICA NÃO-CONSPIRATIVA DA RELAÇÃO ENTRE ASSESSORES DE IMPRENSA E JORNALISTAS}

\section{CONSIDERAÇÕES FINAIS}

Ao contrário do que o senso comum pensa, as notícias não são um espelho da realidade. As notícias resultam, isso sim, de uma construção social e cultural com base no que é extraído das fontes. 0 que ressuma da notícia é não apenas aquilo que acontece no mundo real, mas também o tipo de relações profissionais, sociais e culturais que se estabelecem entre os jornalistas e as suas fontes.

Esta constatação entronca na ideia, hoje aparentemente consensual, de que a fonte é, na maioria dos casos, o ponto de partida do processo de produção noticiosa. Neste pressuposto, o trabalho do jornalista sofre fortes constrangimentos, ou é pura e simplesmente inviável, sem o acesso a fontes de informação. Por outro lado, a qualidade da notícia depende muito da qualidade da fonte (ou das fontes) que esteve (estiveram) na sua origem. Daí que exista uma 'hierarquia de credibilidade' entre as fontes, que o jornalista respeita na expectativa de garantir uma informação mais rigorosa e qualificada. Acontece, porém, que essa hierarquia leva os jornalistas a tendencialmente privilegiarem as fontes de informação próximas ou que representam o poder, em detrimento das fontes ligadas a grupos ou indivíduos com menor influência social.

A 'hierarquia de credibilidade' é, sem dúvida, uma tendência muito forte no jornalismo contemporâneo. Mas daqui não se pode inferir que a hegemonia das fontes de informação profissionais é inexorável, nem que o relacionamento entre estas fontes de maior sofisticação e os jornalistas obedece a um padrão de comportamento rígido, imutável, monolítico. Na verdade, toda essa dinâmica em torno da produção noticiosa é bem mais complexa e diversificada. Se, por um lado, as elites têm maior capacidade para condicionar e até definir a agenda mediática em função dos seus interesses, por outro, é também inegável que essas mesmas elites são as mais fustigadas por notícias que prejudicam a sua imagem pública. É preciso não esquecer que, apesar de tudo, ainda prevalece no jornalismo uma lógica de contrapoder, que impede as minorias poderosas de controlar em absoluto os conteúdos veiculados pelos media.

Ainda assim, a capacidade das fontes profissionais de fornecer dados pertinentes e de criar eventos noticiáveis atingiu um elevado grau de sofisticação, com tudo o que isso significa em termos de exponenciação da eficácia da chamada informação subsidiada. De fato, assessores de imprensa estão cada vez mais sofisticados na arte de formatar estórias segundo as regras e linguagens jornalísticas, oferecendo pragmaticamente uma espécie de alimento pré-cozinhado aos jornalistas. Os jornalistas veem o seu trabalho ser assim extremamente simplificado e, por vezes, sucumbem ao facilitismo durante o processo de produção noticiosa - embora, em alguns casos, por fatores a que são alheios, como a pressão para cumprir os deadlines.

Nesse contexto, fontes e jornalistas criam entre si uma relação, que decorre da percepção de que juntos conseguem mais facilmente concretizar os seus objetivos. Tal não significa, porém, que esses objetivos sejam coincidentes e sempre conciliáveis. Para a fonte profissional, o importante é promover a mediatização de acontecimentos favoráveis às suas organizações (ou aos indivíduos) e evitar a publicitação de tudo o que for penalizador das mesmas. Por seu turno, 0 jornalista procura noticiar fatos que se desviam da norma (o homem que mordeu o cão, para dar um exemplo clássico) e, consequentemente, desvaloriza o goodwill dos acontecimentos com que a fonte o tenta seduzir. É uma relação simbiótica que muitas vezes resulta em alguma tensão ou mesmo de conflitualidade.

Perante tudo isso, não é possível identificar padrões e modelos rígidos de relacionamento entre as fontes profissionais e os jornalistas, sendo certo, porém, que podem ser desenhados comportamentos e tendências que nos permitem conhecer melhor o 'campo' da assessoria de imprensa. 
No fundo, a chave para uma relação profícua entre fonte e jornalista está na idoneidade de ambos. De uma fonte esperase credibilidade, rigor factual e conhecimento superlativo - atributos que são compatíveis com a defesa dos legítimos e pragmáticos interesses das organizações ou dos indivíduos que elas representam. Dos jornalistas espera-se respeito pelas regras deontológicas da profissão, uma aguda noção do que é o interesse público e um tributo às regras de produção das notícias - atributos que são compatíveis com o processo negocial que, as mais das vezes, a relação com as fontes obriga. Aliás, quanto mais o jornalismo conhecer os modelos de atuação da assessoria de imprensa, melhor cumpre a sua nobre missão.

\section{REFEREANCIAS}

ALTHEIDE, D. L. Creating reality. how tv news distorts events. London: Sage Publications, 1976.

BERLO, D. The process of communication: an introduction to theory and practice. Michigan: Holt, Rinehart and Winston, 1960. O processo da comunicação: introdução à teoria e à prática. 10. ed. São Paulo: Martins Fontes, 2003.

BOORSTIN, D. J. The image: a guide to pseudo-events in América. New York: Atheneum, 1961.

CHAPARRO, M. C. Linguagem dos conflitos. Coimbra: Minerva, 2001.

COOK, T. E. Making laws and making news. media strategies in the U.S. House of Representatives. Washington, DC: Brookings Institution, 1989.

Governing with the news. the news as a political institucion. Chicago and London: The University od Chicago Press, 1998.

CURRAN, J. Rethinking mass communication. In: CURRAN, J. et al. (Ed.). Cultural studies and communications. London: Hodder Arnold, 1996.

Mediations of democracy. In: CURRAN, J.; GUREVITCH, M. (Ed.). Mass media and society. London: Hodder Arnold, 2005. p. 122-149.

DAVIES, N. Flart earth news. an award-winning reporter exposes falsehood, distortion and propaganda in the global media. London: Chatto \& Windus, 2008.

ERICSON, R. V.; BARANEK, P. M.; CHAN, J. B. L. Visualizing deviance: a sutudy of news organization. Stony Stratford: Open University Press, 1987.

Negotiating control: a study of news sources. Toronto: University of Toronto Press, 1989.

FISHMAN, M. Manufacturing the news. Austin, TX: University of Texas Press, 1980.

FRANKLIN, B.; LEWIS, J.; WILLIAMS, A. Journalism, news sources and public relations. In: ALLAN, S. (Ed.). The Routledge companion to news and journalism. New York: Routledge, 2010. p. 202-212.

GALTUNG, J.; RUGE, M. H. The structure of foreign news. Journal of Peace Research, v. 2, n. 1, p. 64-91, 1965.

GANDY, O. H. Beyond agenda setting: information subsidies and public policy. [S. L.]: Ablex Pub. Co., 1982. 
GANS, H. J. Deciding what's news: a study of CBS Evening News, NBC Nightly News, Newsweek and Time. Evanston, IL: Northwestern University Press, 1979.

GUMG - Glasgow University Media Group. Getting the message: news, truth and power. London and New York: Routledge, 1993.

Glasgow University Media Group. A reader. news content, language and visuals. (1980). London and New York: Routledge, 1995.

HALL, S. et al. A produção social das notícias: 0 "mugging" nos media. In: TRAQUINA, N. (Ed.). Jornalismo: questões, teorias e "estórias". Lisboa: Vega, 1993 [1973]. p. 224-248.

HERMAN, E.; CHOMSKY, N. Manufacturing consent. London: Pantheon Books, 1988.

HESS, S. The government/press connection: press officers and their offices. Washington, DC: The Brookings Institution, 1984.

MANNING, P. Spinning for labour: trade union and the news media enviroment. Hants, Ashgate Publishing Company, 1998.

News and news sources: a critical introduction. London; Thousand Oaks, Calif: Sage Publications, 2001.

MENCHER, M. News reporting and writing. Dubeque, IA: Wm. C. Brown Publishers, 1991 [1977].

MICHIE, D. The invisible persuaders: how Britain's spin doctors manipulate the media. London: Bantam Press, 1998.

MOLOTCH, H.; LESTER, M. As notícias como procedimento intencional: Acerca do uso estratégico de acontecimentos de rotina, acidentes e escândalos. In: TRAQUINA, N. (Ed.). Jornalismo: questões, teorias e "estórias". Lisboa: Vega, 1993. p.42-51.

PACKARD, V. The hidden persuaders. New York: IG Publisher, 1957.

PALMER, J. Spinning into control. London and New York: Leicester University Press, 2000.

RAMONET, I. Propagandas silenciosas. massas, televisão e cinema. Lisboa: Campo das Letras, 2000.

RIBEIRO, V. Fontes sofisticadas de informação: análise do produto jornalístico político da imprensa nacional diária de 1995 a 2005. Media \& Jornalismo, v. 9, n. 17, p. 231-246, 2010.

ROSHCO, B. The evolution of news content in the American politics. In: GRABER, D. (Ed.). Media power in politics. Washington, DC: CG Press, 1984. p.7-22.

SCHLESINGER, P. Rethinking the sociology of journalism: Source strategies and the limits of media-centrism. In: FERGUSON, M. (Ed.). Public communication: the new imperatives. London: Sage Publications, 1990. p. 61-83.

TUNSTALL, J. Journalists at work. Specialist correspondents: their news organizations, news sources, and competitorcolleagues. London: Sage Publications, 1974.

Artigo recebido em 02.03.2015 e aprovado em 01.06.2015. 